\title{
CORRECTION
}

\section{Correction to: Quest for the Best Evolutionary Model}

\author{
Rafael Zardoya ${ }^{1}$ (D)
}

Published online: 14 January 2021

(c) Springer Science+Business Media, LLC, part of Springer Nature 2021

\section{Correction to: Journal of Molecular Evolution}

https://doi.org/10.1007/s00239-020-09971-z

The original version of the article unfortunately contained an error in Figure 2. Incorrect version of Dr. Taka-aki Yano has been published. Figure 2 with the corrected image of Dr. Taka-aki Yano is given below.

The original article has been corrected.

Publisher's Note Springer Nature remains neutral with regard to jurisdictional claims in published maps and institutional affiliations.

The original article can be found online at https://doi.org/10.1007/ s00239-020-09971-z.

Rafael Zardoya

rafaz@mncn.cisc.es

1 Departamento de Biodiversidad y Biología Evolutiva,

Museo Nacional de Ciencias Naturales (MNCN-CSIC), José

Gutiérrez Abascal, 2, 28006 Madrid, Spain 


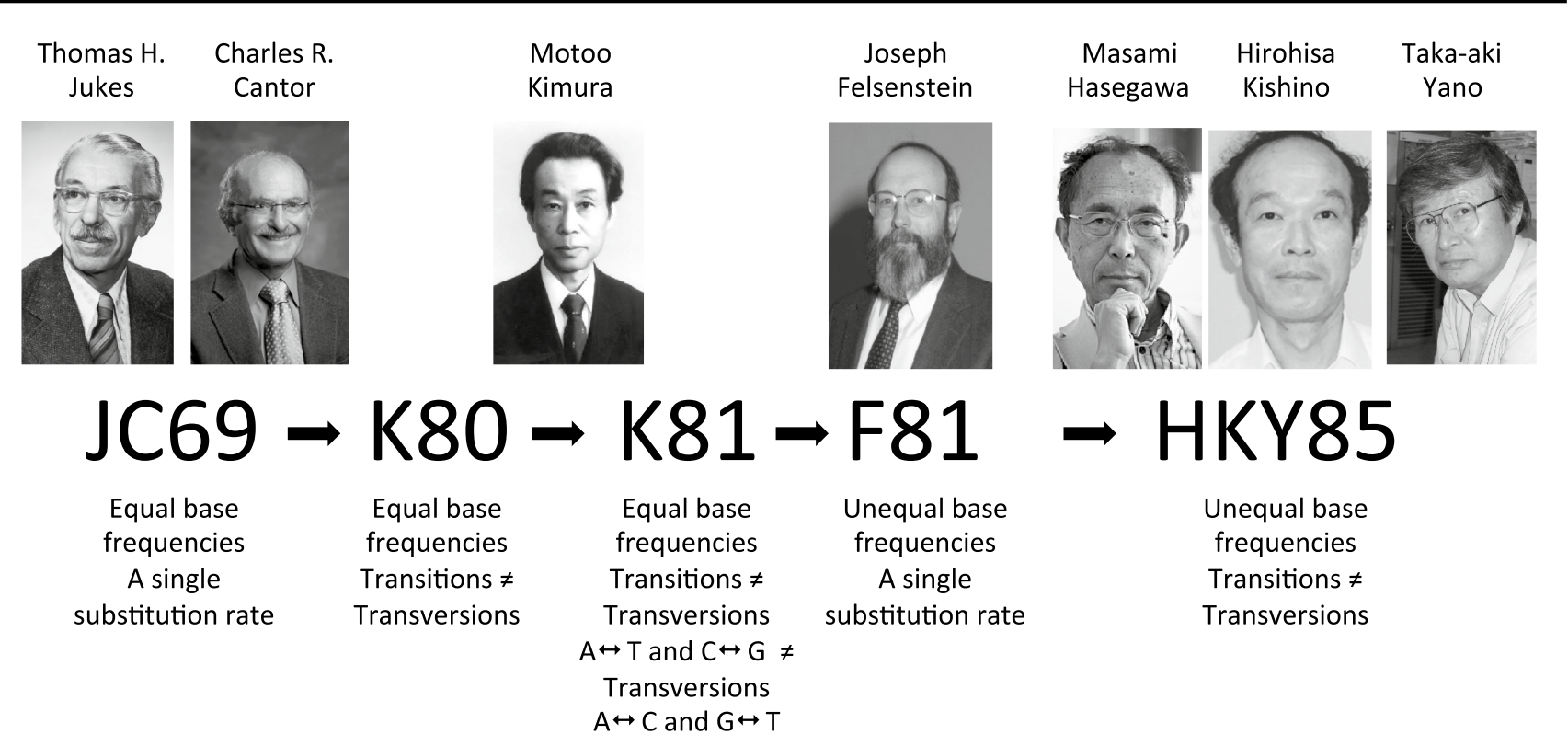

Fig. 2 The quest for the best evolutionary model. The simplest nucleotide substitution model (JK69; (Jukes and Cantor 1969) was improved in the early 1980 s by adding parameters that either assumed different types of substitution (K80, K81; Kimura 1980, 1981), unequal base frequencies (F81; (Felsenstein 1981) or both (HKY85; (Hasegawa et al. 1985) 